\title{
EXPERIMENTAL SETUP OF FLUID MIXING IN DOUbLE TEE-JUNCTIONS
}

\author{
Ivana Lučin, Lado Kranjčević, Zoran Čarija \& Antonio Mogorović
}
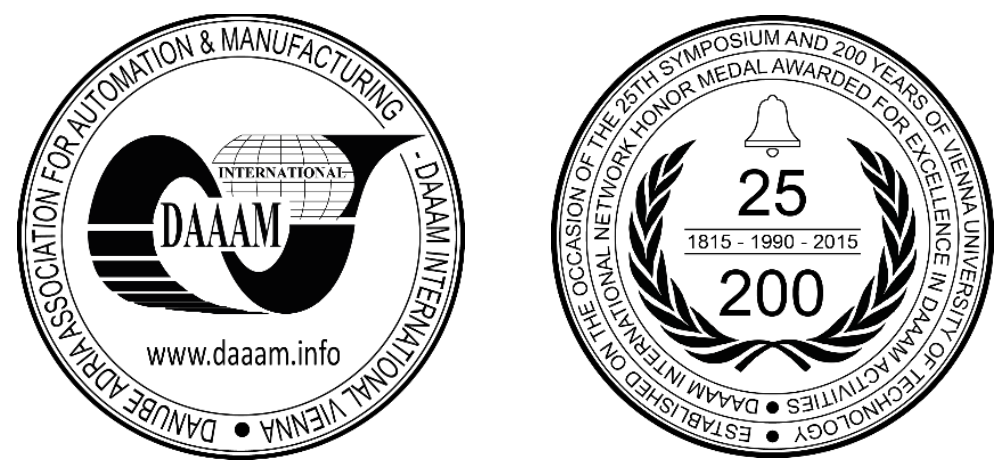

This Publication has to be referred as: Lucin, I[vana]; Kranjcevic, L[ado]; Carija, Z[oran] \& Mogorovic, A[ntonio] (2018). Experimental Setup of Fluid Mixing in Double Tee-Junctions, Proceedings of the 29th DAAAM International Symposium, pp.1059-1064, B. Katalinic (Ed.), Published by DAAAM International, ISBN 978-3-902734-20-4, ISSN 1726-9679, Vienna, Austria

DOI: $10.2507 / 29$ th.daaam.proceedings.151

\begin{abstract}
Water quality control is of great importance. Since water is being distributed through large complex pipe networks both hydraulic and water quality analysis of these systems are conducted with computer engineering programs. Pipe networks consist of various elements that influence fluid flow and it is important to understand their impact on complex phenomena like mixing. Computer programs simplify mixing effects at junctions and they lack data to fully describe the nature of mixing. Experimental methods are used to provide additional parameters that would improve the results of computer simulations that would provide more accurate prediction of water and pollution transport through pipe systems. In this work, an experimental methodology is presented which could be used to observe the influence of distances between two tee-junctions and different inflow rates on mixing. Also, data gathered from experiment can provide more accurate mixing parameters for improvement of computer simulations.
\end{abstract}

Keywords: mixing; experiment; double tee-junction; pipe network; pollution

\section{Introduction}

To fulfill the water demand of a continuously growing population, pipe networks were constructed to transport water to many users. A water distribution network is a complex system because it consists of various elements such as pipes, valves, tanks, junctions etc. Typical pipe junctions that are used are cross and tee junctions as seen in figure 1 . Teejunctions as shown in figure 2 are an important part of water distribution networks.

It is of great importance to keep the quality of water under control and because of that it is necessary to monitor the effects of mixing that is important in case of pollution in a distribution network. Mixing and transport at junctions are complicated phenomena due to numerous reasons, effects like secondary currents at junctions or flow instabilities greatly enhance turbulence and mixing. 
(a)

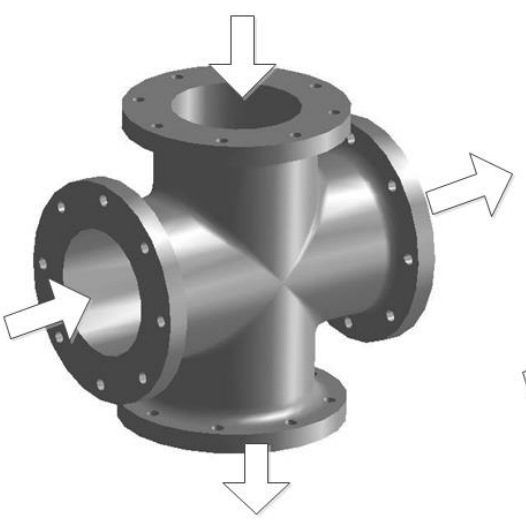

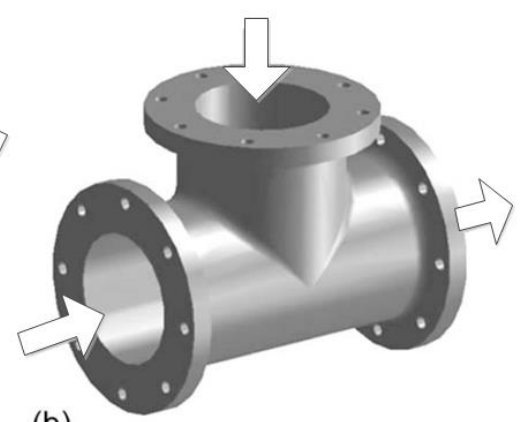

(b)

Fig. 1. Typical pipe junctions: a) cross junction; b) tee junction

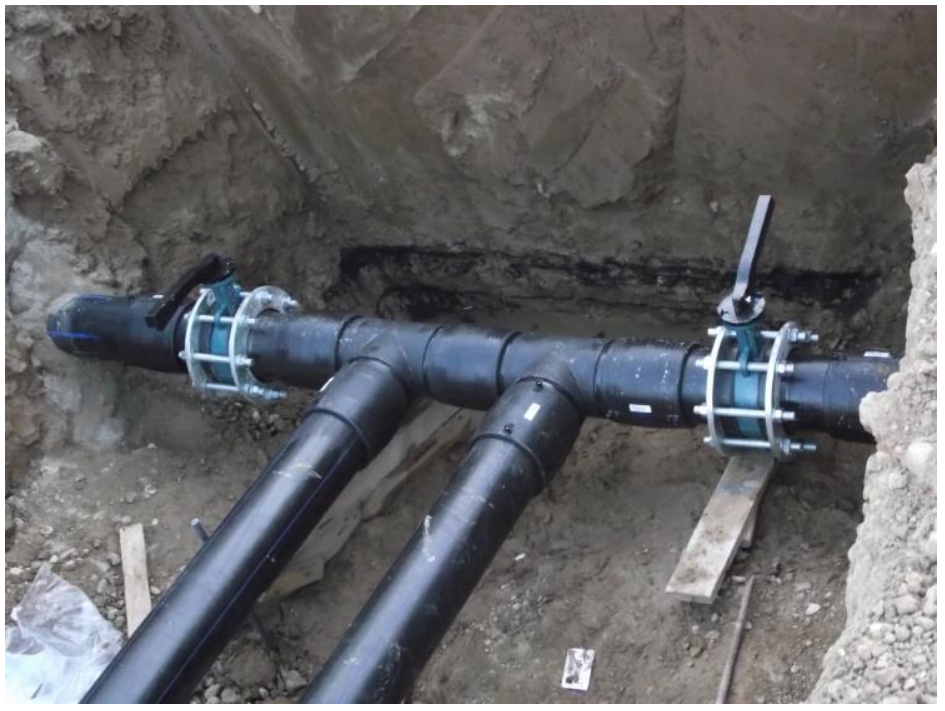

Fig 2. Double tee junction in pipe network, Reference: http://gspservice.ru

Due to great complexity of water systems investigation of water flow characteristics in pipe networks is done with numerical simulations and also water resource scheduling [1],[2]. These simulations are also used to predict contamination source detection or to predict contamination propagation in water distribution network [3]. The most used computer engineering programs for hydraulic analysis and water quality modelling are EPANET which is developed by the Environmental Protection Agency [4] and AFT Fathom [5]. The Hardy-Cross method described [6] is widely used for pipe network analysis problems. Solute trajectory is most affected at the junctions and it is difficult to predict its behaviour. Many current water quality models in pipe networks are based on a simple assumption of instantaneous complete mixing. EPANET [4] assumes complete mixing at every junction in a simulated water distribution network. This could be considered correct but only if there is a single outlet at a junction.

When modelling more complex flow such as those at a cross junction or a double tee-junction, number of studies have shown that mixing in those cases is far from complete and to make that assumption could yield considerable errors [7], [8], [9], [10], [11], [12]. Flows that are merging at a junction have shown a tendency to bifurcate and reflect from each other rather than to mix completely. EPANET was upgraded with extension EPANET-BAM [13] which is based on a bulk advective mixing model. This model uses a mixing parameter which defines the characteristics of mixing and it is a value between 0 and 1, where 0 is bulk mixing and 1 is complete mixing. Bulk mixing ignores flow instabilities and diffusion at the points where two currents are touching. There is a further EPANET-BAM extension called BAM-WRAP [12] and it provides analysis for pipes that are of unequal sizes and it assumes that flow can be divided into core and wraparound region. It is worth noting that both extensions of EPANET need predetermined mixing parameters which still cannot be precise enough so to determine solute concentration distribution in a pipe network remains a challenge.

In this work experimental methodology will be presented that will provide better insight in mixing phenomena. With these results mixing parameters used in computer engineering programs could be adjusted to provide more realistic solutions and also enhancement of used methods could be made. In the experiment, mixing in double tee-junctions was evaluated, where distances between tee-junctions were changed to measure the influence on complete mixing. 


\section{Materials and methods}

Experimental setup was constructed in the laboratory of the Faculty of Engineering at the University of Rijeka shown at figure 3. Setup consisted of double tee-junctions, pipes with $18 \mathrm{~mm}$ internal diameter and $22 \mathrm{~mm}$ outer diameter. All elements in the experiment are made of PVC. The length of the both fluid inlet pipes was set 20 times the internal diameter (20D) which is considered long enough to develop turbulent flow and both outlet pipes have the length of 40D. In Shao [14], the influence of distances between junctions and flow rates were considered. Distances between junctions that were investigated were up to $10 \mathrm{D}$, due to assumptions that complete mixing in double tee- junctions occurs in the same way as in a single tee junction where two inlet streams converge in a single outlet where complete mixing was noticed at around $10 \mathrm{D}$ [15]. In our experiment the pipe lengths between the junctions were set as 5.6D, 10D and 15D. The 5.6D distance was the smallest one that could be used due to physical limitations of tees design.

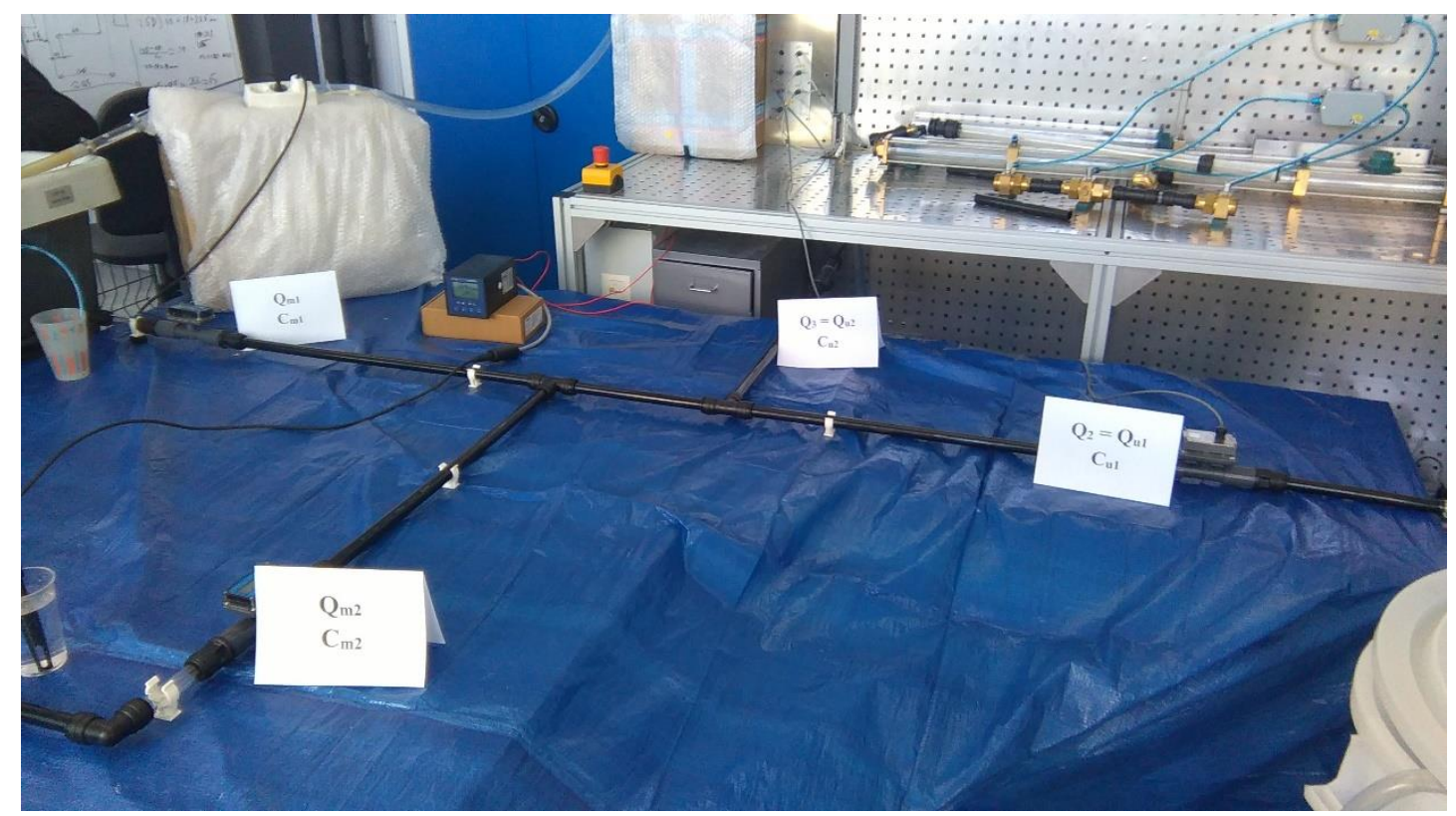

Fig. 3. Experimental setup

For all experimental runs inlet 1 was the inlet of tap water that was considered as the tracer and inlet 2 was the inlet of distilled water that was considered as clean water so the conductivity was different. Inlet flows Q1 and Q2 were regulated with valves to obtain the same flow ratio which was around $0.2 \mathrm{l}$ /s. Fluid conductivity of tap water $(\mathrm{C} 1)$ and conductivity of distilled water (C2) were measured before every experimental run. Outlet 3 and outlet 4 were the mixture outlets where fluid flow Q3 and flow Q4 were regulated with valves to have the same value. Fluid conductivity C3 and $\mathrm{C} 4$ were measured to observe the effects of mixing fluids with different conductivity. Details of the double tee- junctions for distance of 5.6D with labelled flows and concentrations is shown in figure 4.

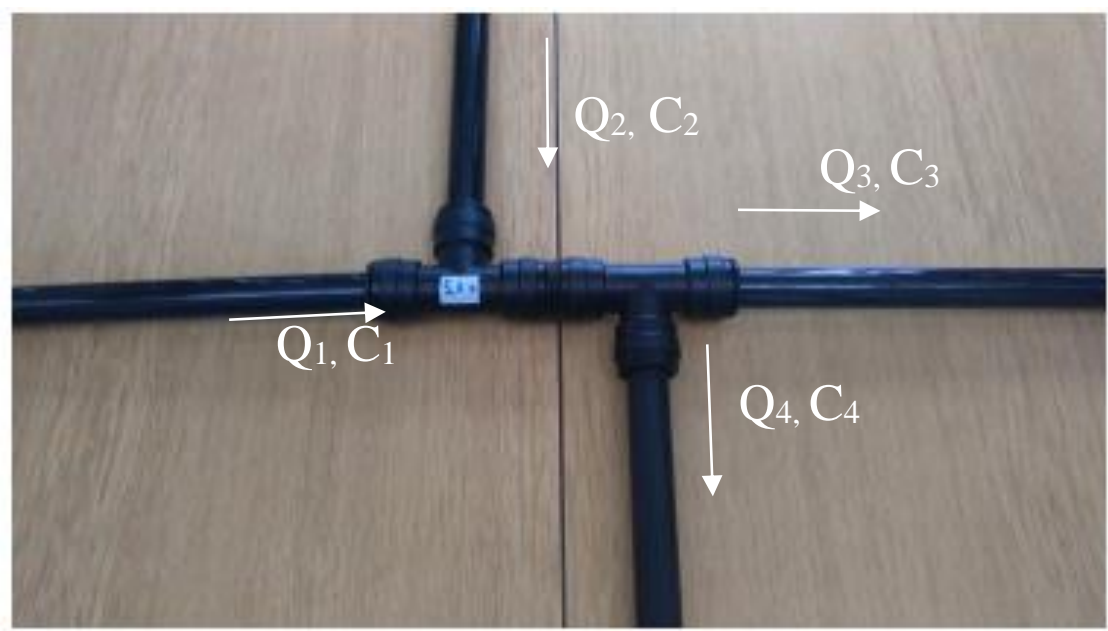

Fig. 4. Double tee-junction experimental setup 
Conductivity was measured with conductivity sensor WTW TetraCon 325 used with WTW LF 296 conductivity monitor made by WTW GmbH as seen on figure 5. For every measurement conductivity C3 and C4 were measured when steady state fluid flow occurred.
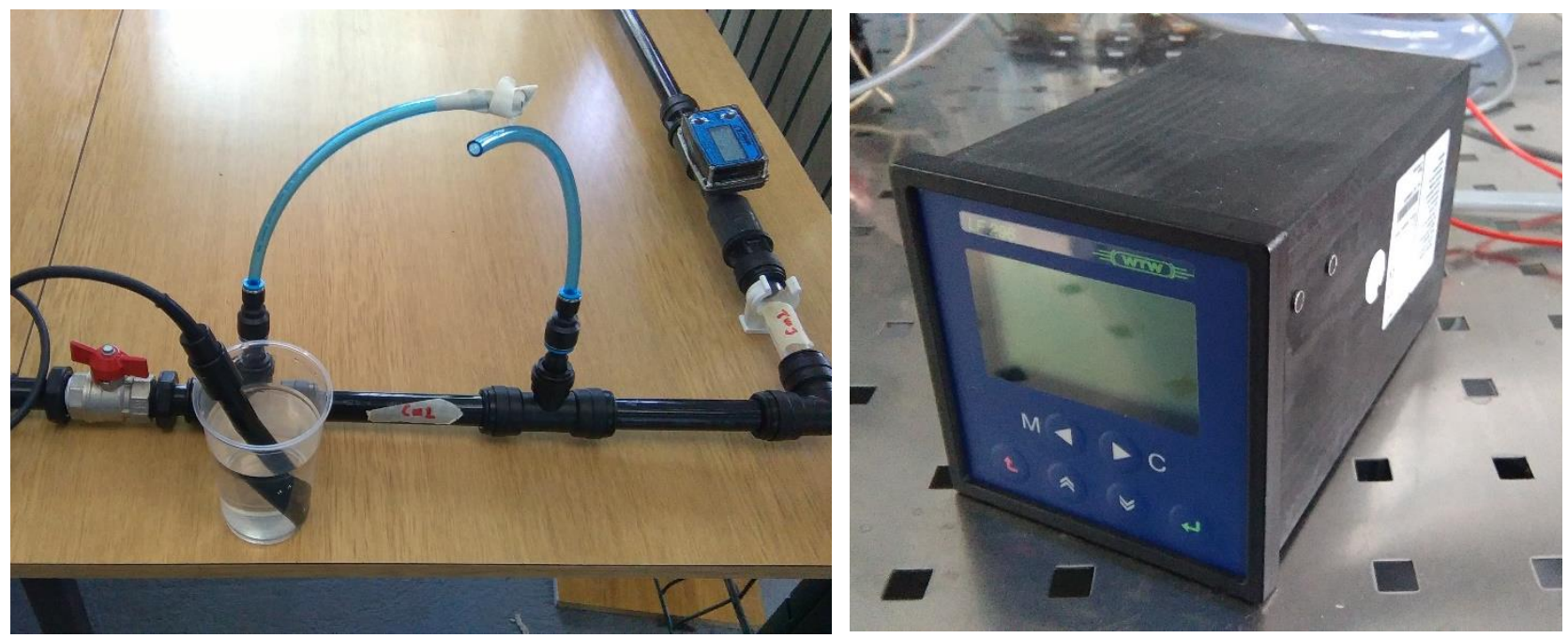

Fig. 5. Conductivity measurement equipment

\section{Results and discussion}

With known inlet and outlet flows, which were regulated with valves to be the same, experimental results are presented in table 1. It can be observed that with greater distance between junctions, deviation from complete mixing is reduced. As can be seen from the results, due to insufficient valve regulation sensitivity, same flows could not be accomplished for all experiments and small deviation in measured outlet flow rates was present.

Due to natural unsteady nature of fluid flow in pipes, flow measurements showed small oscillations during experiment. Contrary to previous literature [14], in this experiment complete mixing was still not observed with the distance of 15D. This indicates that future investigation should be made with greater distances to find the exact distance that produces complete mixing.

\begin{tabular}{|c|c|c|c|c|}
\hline \multirow{2}{*}{$\begin{array}{c}\text { Distance between } \\
\text { junctions }\end{array}$} & \multicolumn{2}{|c|}{ Inlet flow rates } & \multicolumn{2}{|c|}{$\begin{array}{c}\text { Deviation from complete } \\
\text { mixing }\end{array}$} \\
\cline { 2 - 5 } & $\mathrm{Q} 1[1 / \mathrm{s}]$ & $\mathrm{Q} 2[1 / \mathrm{s}]$ & $\begin{array}{c}\mathrm{C} 3 \\
{[\mu \mathrm{S} / \mathrm{cm}]}\end{array}$ & $\begin{array}{c}\mathrm{C} 4 \\
{[\mu \mathrm{S} / \mathrm{cm}]}\end{array}$ \\
\hline 5.6 D & 0,21 & 0,21 & $-16,4$ & 16,6 \\
\hline $10 \mathrm{D}$ & 0,2 & 0,2 & $-4,98$ & 12,32 \\
\hline $15 \mathrm{D}$ & 0,27 & 0,27 & $-0,685$ & 7,315 \\
\hline
\end{tabular}

Table 1. Deviation from complete mixing for different distances between junctions

In figure 5 experimental data is compared with previous research [8], [9] where it can be seen that depending on distance between junctions mixing parameter s, that describes the characteristics of mixing, is different. As shown before in table 1 , here it can also be seen that with greater distance between junctions, complete mixing is being approached.The presented methodology of experiment generated expected results and the same methodology can be used for different flow rates and also for different junction configurations.

A greater number of experiments should be conducted, to acquire greater amount of data which would be averaged to produce more reliable results. To resolve the problem regarding oscillations in observed fluid flows, continuous measurements could be made to show the average value of flows throughout the experiment. 


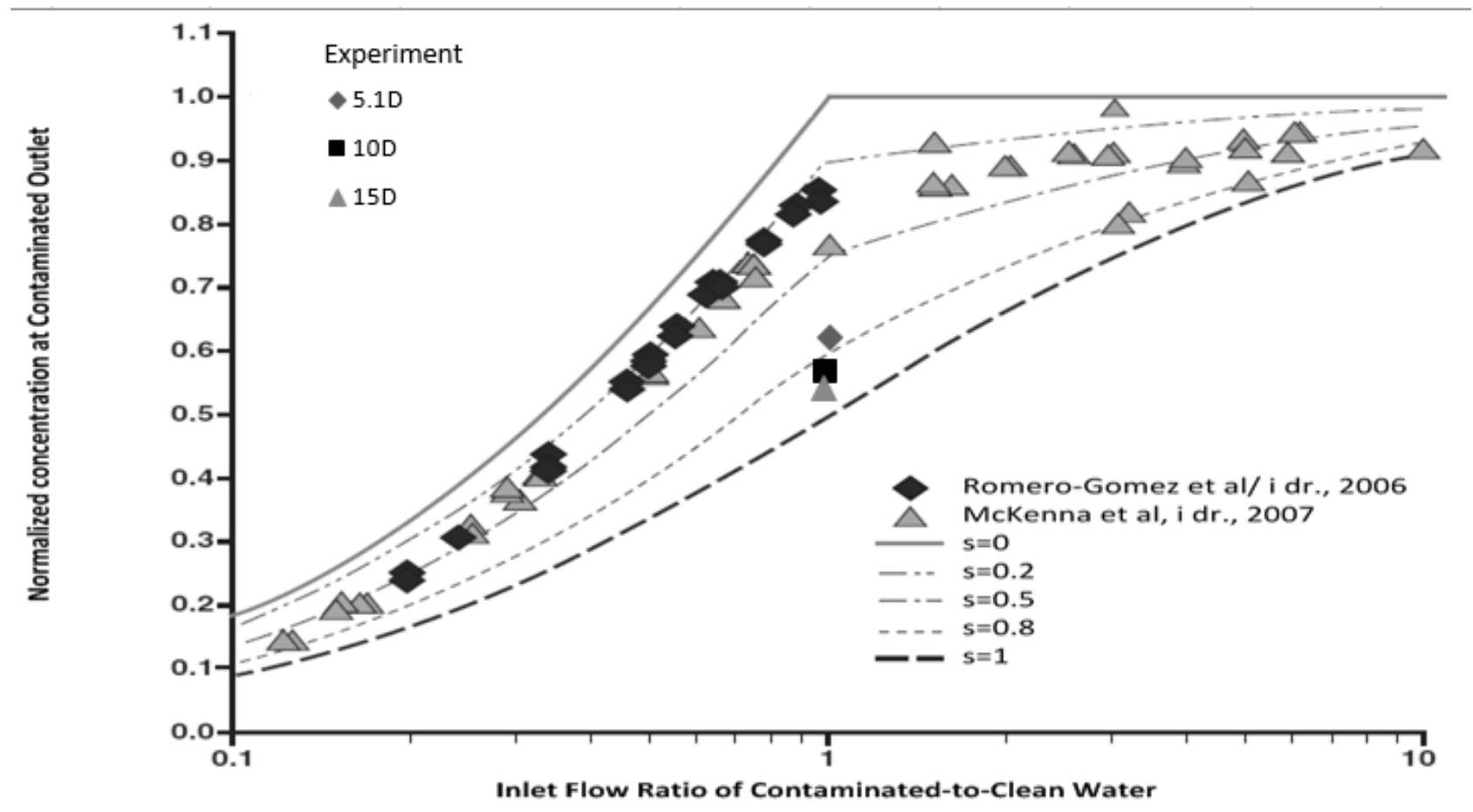

Fig. 6. Experiment comparison with [8] and [9]

\section{Conclusion}

Fluid flow in pipe networks is important for water quality measurements. In case of an incident, computer programs allow us to predict behaviour of fluid flow and appropriate measures can be taken to reduce or prevent damage. In these widely used computer programs, mixing phenomena is described with simplifications that can greatly influence simulation results. In this paper we presented an experimental method that can be used for investigation of mixing phenomena in double tee-junctions placed at different distances.

Further experimental studies should be conducted which would provide greater insight in impact of junction distances, junction orientation and flow rates on complete mixing where results of experiment can be implemented in computer programs to further enhance numerical simulations and their ability to predict contamination propagation in pipe network.

\section{References}

[1] Egri., A., Sirb, V. C., Patrascoiu, N. \& Tomus, A. (2011). Intelligent control and monitoring of drinking water distribution system. Annals of DAAAAM for 2011 \& Proceedings of the 22nd International DAAAM Symposium, Volume 22, No.1, ISSN 1726-9679, ISBN 978-3-901509-83-4, Katalinic, B. (Ed.), pp. 629-630. Published by DAAAM International, Vienna, Austria, EU, 2011.

[2] He, L. X. \& He, S. H. (2015). Solving water resource scheduling problem through an improved artificial fish swarm algorithm. International Journal of Simulation Modelling. Vol. 14, No. 1, pp. 170-181.

[3] Kranjčević, L., Čavrak, M. \& Šestan, M. (2010). Contamination source detection in water distribution networks. Engineering Review. Vol. 30, No. 2, pp. 11-25.

[4] Rossman, L. (2000). EPANET - User's manual, Enivronmental protection (USEPA), United States

[5] Applied Flow Technology Corporation. (2008). AFT Fathom User's Guide, United States

[6] Cross, H. (1936). Analysis of flow in networks of conduits or conductors. University of Illinois at Urbana Champaign, College of Engineering. Engineering Experiment Station.

[7] van Bloemen Waanders, B., Hammond, G., Shadid, J., Collis, S., \& Murray, R. (2005). A comparison of Navier Stokes and network models to predict chemical transport in municipal water distribution systems. Proceedings of World Water and Environmental Resources Congress, ASCE/EWRL, Anchorage.

[8] McKenna, S.A., O'Rear, L., Wright, J.L. (2007). Experimental determination of solute mixing in pipe joints. Proceedings of World Water and Environmental Resources Congress, ASCE/EWRL, Tampa.

[9] Romero-Gomez, P., Choi, C. Y., van Bloemen Waanders B., McKenna, S.A. (2008). Transport phenomena at intersections of pressurized pipe systems. Proceedings of Water Distribution Systems Analysis Symposium 2006., ASCE. 
[10] Choi, C. Y., Shen J. Y., Austin R. (2008). Development of a comprehensive solute mixing model (AZRED) for double-tee, cross and wye junctions. Proceedings of Water Distribution System Analysis 2008., ASCE.

[11] Ho, C. K. (2008). Solute mixing models for water-distribution pipe networks. Journal of Hydraulic Engineering, Vol.134, No. 9, 2008, pp. 1236-1244.

[12] Ho, C. K., O’Rear jr L. (2009). Evaluation of solute mixing in water distribution pipe junctions. Journal-American Water Works Association. Vol. 101, No. 9, pp. 116-127.

[13] Ho, C. K., \& Khalsa, S. S. (2008). EPANET-BAM: water quality modeling with incomplete mixing in pipe junctions. Water Distribution Systems Analysis, 2008, pp. 1-11.

[14] Shao, Y., Yang, Y.J., Jiang, L., Yu, T. \& Shen, C. (2014). Experimental testing and modelling analysis of solute mixing at water distribution pipe junctions. Water research. Vol. 56, pp. 133-147.

[15] Plesniak, M.W. \& Cusano, D.M. (2005). Scalar mixing in a confined rectangular jet in crossflow. Journal of Fluid Mechanics, Vol 524, pp. 1-45. 